\title{
Intramolecular [4 + 2] Cycloadditions of Iminoacetonitriles: A New Class of Azadienophiles for Hetero Diels-Alder Reactions
}

\author{
David T. Amos, Adam R. Renslo, and Rick L. Danheiser ${ }^{\star}$ \\ Department of Chemistry, Massachusetts Institute of Technology, Cambridge, Massachusetts \\ 02139
}

\begin{abstract}
Activated imines which can function as reactive $2 \pi$ components in cycloadditions are valuable building blocks for the construction of nitrogen heterocycles. ${ }^{1}$ In this communication we report on the preparation and intramolecular Diels-Alder reactions of iminoacetonitriles, a class of electron-deficient imines ${ }^{2}$ whose cycloaddition chemistry has not previously been examined. ${ }^{3}$ Our interest in this class of imines derives from the expectation that they should function as reactive partners in a variety of cycloaddition and annulation processes, providing access to cyclic $\alpha$-amino nitriles of diverse ring size (Scheme 1). $\alpha$-Amino nitriles are exceptionally versatile intermediates for the synthesis of nitrogen heterocycles. ${ }^{4}$ Metalation provides opportunities for alkylation and other carbon-carbon bond-forming processes, while exposure to Lewis acids furnishes iminium ions which can be intercepted with Grignard reagents (Bruylants reaction) and organosilanes, or engaged in Mannich reactions and other useful "cation- $\pi$ "-type cyclization processes.
\end{abstract}

Previously, the synthesis of iminoacetonitriles has been achieved by the chlorination of $\alpha$ amino nitriles followed by elimination of $\mathrm{HCl}$ with base.2 In our hands this approach indeed proved workable, but for the preparation of our cycloaddition substrates we have developed a more expeditious route that begins with readily available alcohols5 and employs a Mitsunobu coupling reaction ${ }^{6}$ with the previously unknown, easily prepared reagent, $\mathrm{HN}(\mathrm{Tf}) \mathrm{CH}_{2} \mathrm{CNN}^{7}$ Base-promoted elimination of trifluoromethanesulfinate ${ }^{8}$ then furnishes the desired iminoacetonitriles as a mixture of $E$ and $Z$ isomers, both of which undergo cycloaddition to afford the same product(s). As summarized in Table 1, this protocol allows the efficient conversion of a variety of functionalized alcohols to the desired cycloaddition substrates in excellent overall yield.

Table 2 delineates the scope of the intramolecular iminoaceto-nitrile hetero Diels-Alder reaction. Most cycloadditions proceed smoothly at $85-120^{\circ} \mathrm{C}$ in the presence of BHT (as radical inhibitor), and the $E$ - and $Z$-imines appear to react at similar rates. ${ }^{9,10}$ Interestingly, in most cases the cycloadduct with exo-oriented cyano group is obtained as the major or exclusive product of the reaction. Our observations suggest that the initially formed epimeric cycloadducts equilibrate to afford the axial cyano isomer which is favored as a consequence of the " $\alpha$-amino nitrile anomeric effect." 11

The $\alpha$-amino nitrile moieties incorporated in these cycloadducts constitute latent iminium ions, which upon exposure to mild protic or Lewis acids are unmasked, setting the stage for further useful synthetic transformations. For example, reductive decyanation with $\mathrm{NaBH}_{3} \mathrm{CN}$

(C) 2003 American Chemical Society

*danheisr@mit.edu .

Supporting Information Available: Experimental procedures and characterization for key compounds (PDF). This material is available free of charge via the Internet at http://pubs.acs.org. 
excises the cyano group and furnishes unadorned quinolizidines (e.g., 21) in excellent yield. Especially valuable is the application of the Bruylants reaction for further carbon-carbon bond construction, as illustrated with the conversion of cycloadduct $\mathbf{2 0}$ to the $\alpha$-alkynylamine $\mathbf{2 2}$ (Scheme 2).

Of particular significance are the stereocomplementary transformations outlined in Scheme 3. Alkylation of the metalated nitrile with ethyl iodide followed by reductive decyanation furnishes exclusively the endo-ethyl product 23, while Bruylants reaction with EtMgBr leads predominantly to the diastereomeric quinolizidine $\mathbf{2 4}$ via exo addition to the less sterically encumbered face of the intermediate iminium ion.

The availability of substituted quinolizidines such as $\mathbf{2 3}$ and $\mathbf{2 4}$ via this strategy is noteworthy, since systems of this type are not available via cycloadditions of iminium ions according to the method of Grieco. ${ }^{12}$ Thus, while the formiminium ion derivative of amine $\mathbf{2 5}$ undergoes smooth cycloaddition in water at $65{ }^{\circ} \mathrm{C}$ (eq 1), analogous reaction of 25 with propanal fails to deliver any of the corresponding $\alpha$-substituted product $\left(\mathrm{R}^{1}=\mathrm{Et}\right) .{ }^{13}$

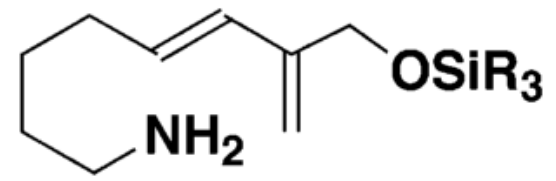

$25 \mathrm{SiR}_{3}=\mathrm{Sit}-\mathrm{BuMe}_{2}$

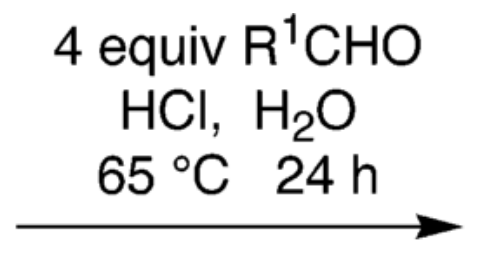

\section{$26 \mathbf{R}^{1}=\mathbf{H} \quad 63-66 \%$}

(1)

Further studies on the application of iminoacetonitriles in organic synthesis are underway and will be reported in due course.

\section{Supplementary Material}

Refer to Web version on PubMed Central for supplementary material.

\section{Acknowledgments}

We thank the National Institute of Health (GM 28273), Pharmacia, and the Merck Research Laboratories for generous financial support. D.T.A. was supported in part by NIH Training Grant CA 09112.

\section{References}

(1). (a) Tietze LF, Kettschau G. Top. Curr. Chem 1997;189:1.(b) Boger, DL.; Weinreb, SM. Hetero DielsAlder Methodology in Organic Synthesis. Academic; San Diego: 1987.

(2). (a) Boyer JH, Dabek H. J. Chem. Soc., Chem. Commun 1970:1204. (b) Boyer JH, Kooi J. J. Am. Chem. Soc 1976;98:1099. (c) De Kimpe N, Verhé R, De Buyck JC, Schamp N. Synthesis 1978;895

(3). For examples of oximinomalonitrile cycloadditions, see: (a) Biehler J-M, Fleury J-P. J. Heterocycl. Chem 1971;8:431. (b) Fleury J-P, Desbois M, See J. Bull. Soc. Chim. Fr 1978:II-147. (c) Bland DC, Raudenbush BC, Weinreb SM. Org. Lett 2000;2:4007. [PubMed: 11112629]

(4). (a) Enders D, Shilvock JP. Chem. Soc. Rev 2000;29:359.(b) Rubiralta, M.; Giralt, E.; Diez, A. Piperidine: Structure, Preparation, Reactivity, and Synthetic Applications of Piperidine and its 
Derivatives. Elsevier; Amsterdam: 1991. p. 225-312. (c) Husson H-P, Royer J. Chem. Soc. Rev 1999;28:383.

(5). Alcohols 1-5 are available in two to four steps. For 1, see Margot C, Rizzolio M, Schlosser M. Tetrahedron 1990;46:2411. For 4, see Ihara M, Taniguchi T, Yamada M, Tokunaga Y, Fukumoto K. Tetrahedron Lett 1995;36:8071. Preparation of alcohols 2, 3, and 5 will be reported in the full paper.

(6). (a) Hughes DL. Org. React 1992;42:335. (b) Hughes DL. Org. Prep. Proced. Int 1996;28:127.

(7). Prepared using the general method of Hendrickson JB, Bair KW, Bergeron R, Giga A, Skipper PL, Sternbach DD, Wareing JA. Org. Prep. Proced. Int 1977;9:173.

(8). For a related elimination, see: Hendrickson JB, Bergeron R, Giga A, Sternbach D. J. Am. Chem. Soc 1973;95:3412.

(9). Cycloadditions of substrates with three-atom tethers (leading to indolizidine products) also proceed in good yield, albeit more slowly; details will be discussed in the full paper.

(10). Control experiments indicate that the $E$ - and $Z$-imines are in equilibrium under the conditions of the reaction.

(11). Bonin M, Romero JR, Grierson DS, Husson H-P. J. Org. Chem 1984;49:2392.

(12). (a) Larsen SD, Grieco PA. J. Am. Chem. Soc 1985;107:1768. (b) Grieco PA, Parker DT. J. Org. Chem 1988;53:3325.

(13). Grieco similarly reports that only iminium ions derived from formaldehyde participate in efficient aza Diels-Alder reactions in aqueous solution. ${ }^{12 \mathrm{a}}$ 


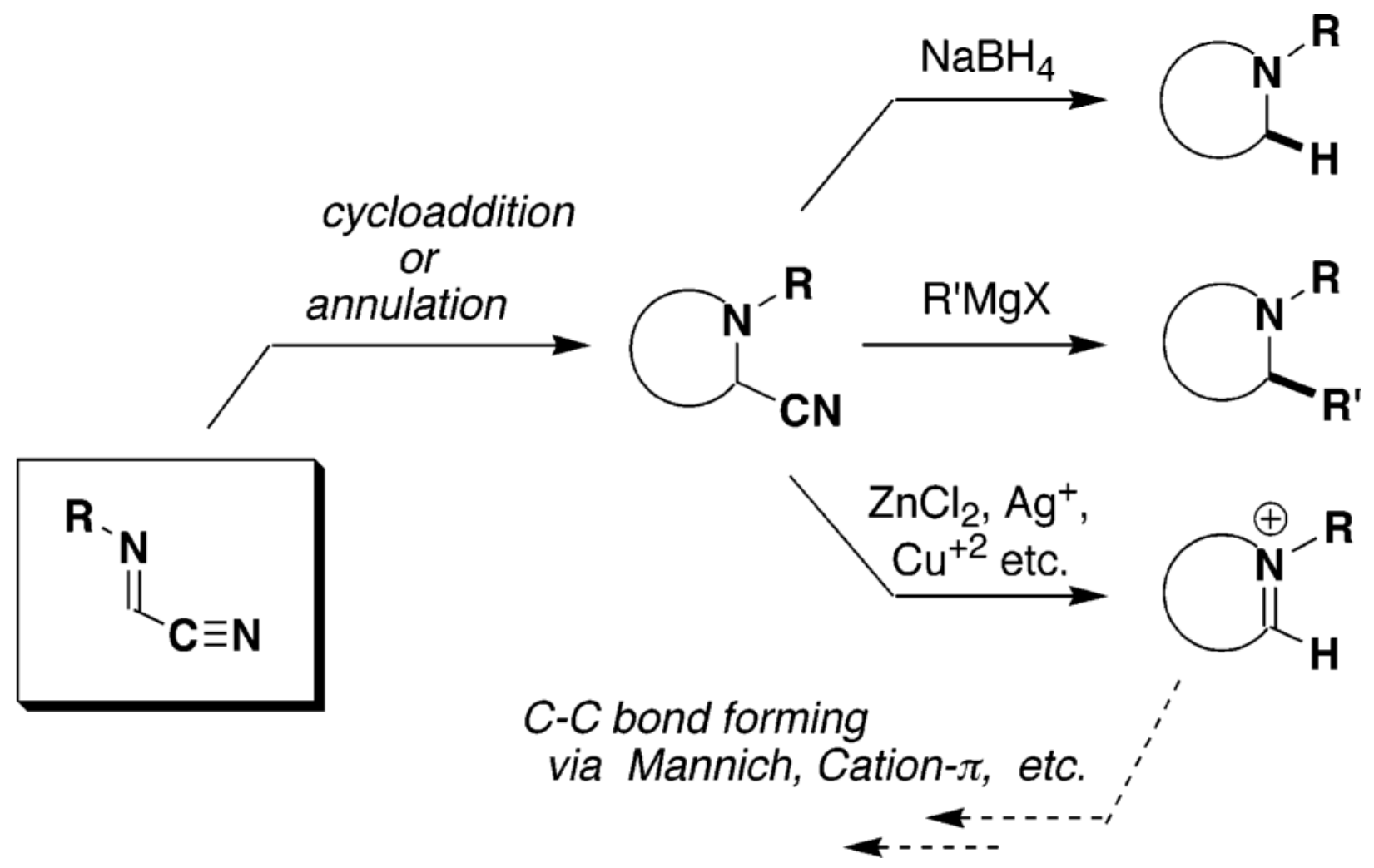

Scheme 1. 

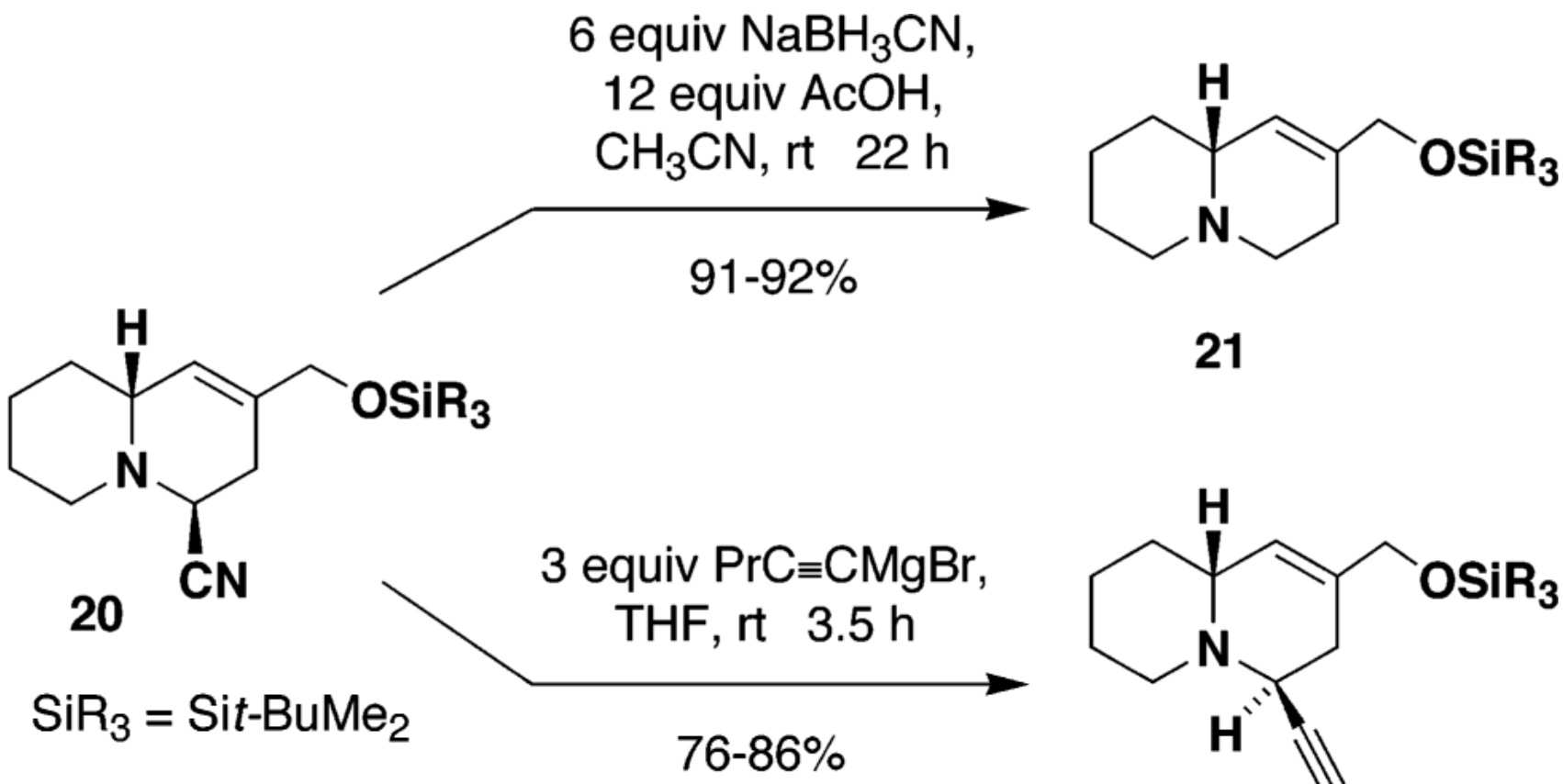

21

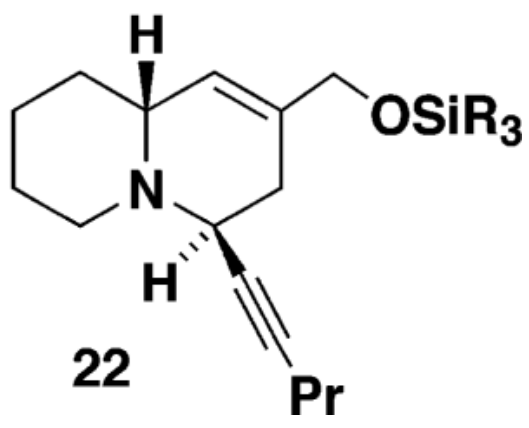

Scheme 2. 


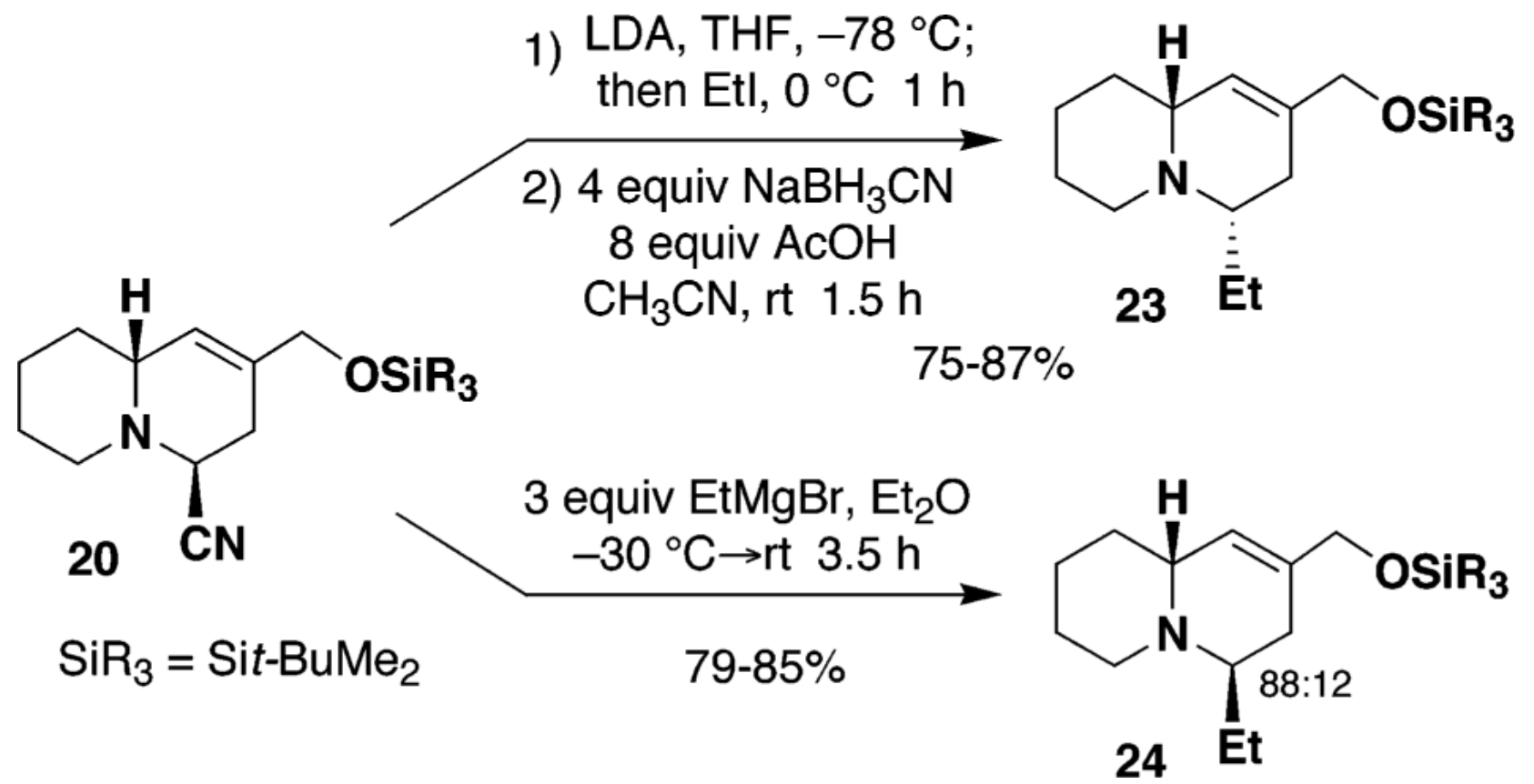

Scheme 3. 


\section{Table 1}

Synthesis of Iminoacetonitriles
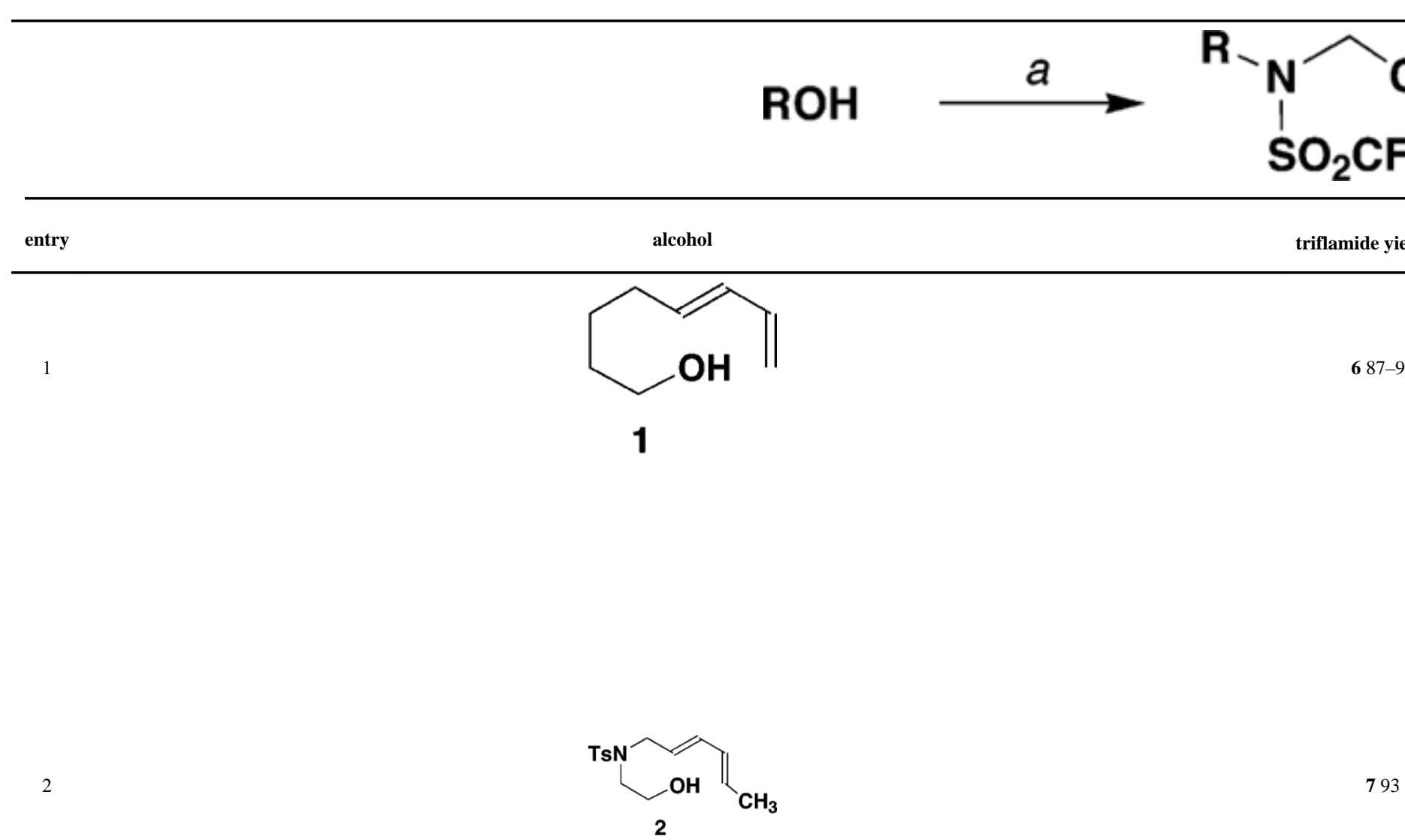


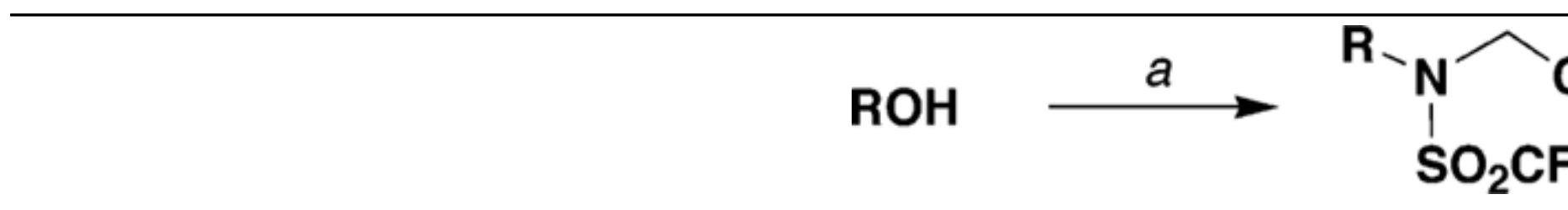

\begin{tabular}{ll}
\hline entry & alcohol \\
\hline
\end{tabular}

triflamide yi

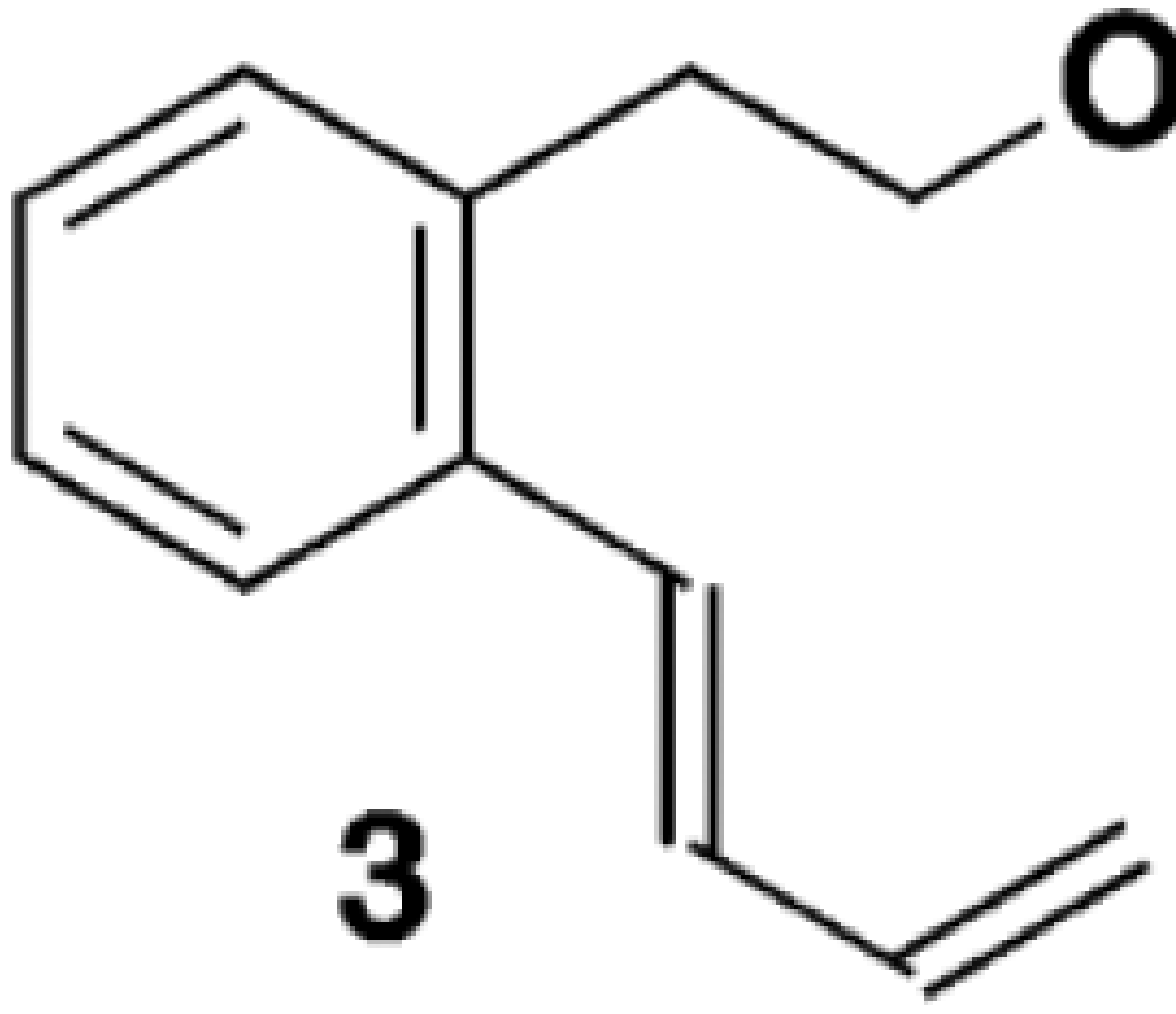



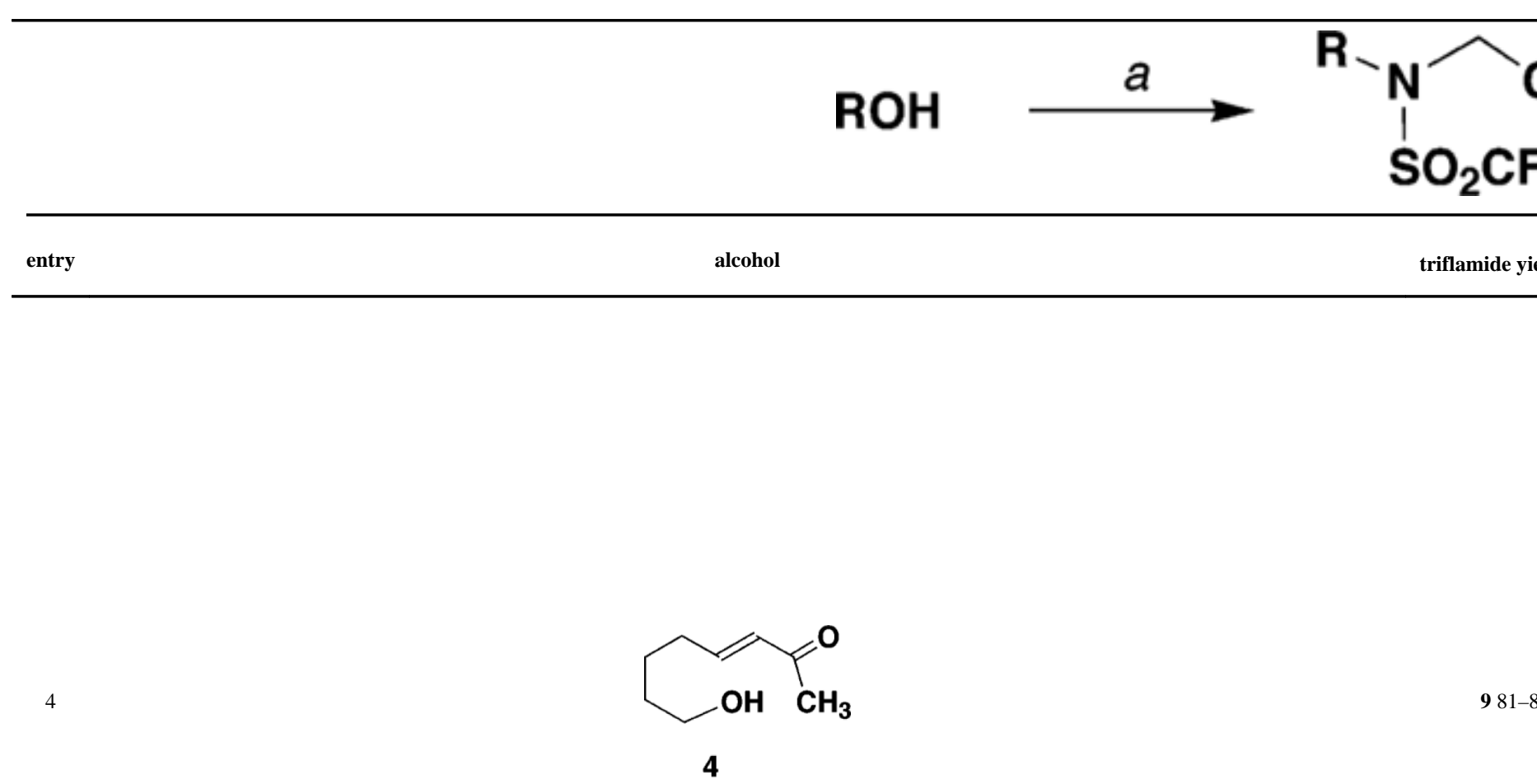

$981-8$

5

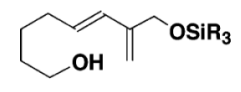

$5 \quad \mathrm{SiR}_{3}=\mathrm{Sit}-\mathrm{BuMe}_{2}$

10 81-

\footnotetext{
$a_{1.05}$ equiv $\mathrm{HN}(\mathrm{Tf}) \mathrm{CH}_{2} \mathrm{CN}, 1.2$ equiv $\mathrm{Ph}_{3} \mathrm{P}, 1.2$ equiv DEAD, $1: 1 \mathrm{THF}-$ toluene, rt, $0.5-4 \mathrm{~h}$ ( $22 \mathrm{~h}$ for entry 2 ).

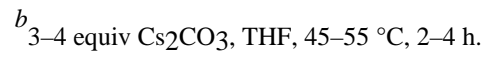

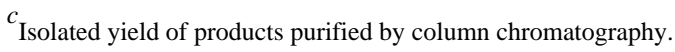

${ }^{d}$ Enone 9 was converted to the dienol silyl ether ( $t$-BuMe $2 \mathrm{SiCl}_{1}, \mathrm{NaI}, \mathrm{Et} 3 \mathrm{~N}, \mathrm{CH}_{3} \mathrm{CN}, \mathrm{rt}, 16 \mathrm{~h}, 96-97 \%$ yield) prior to elimination with $\mathrm{Cs}_{2} \mathrm{CO}_{3}$.
} 
Table 2

$[4+2]$ Cycloadditions of lminoacetonitriles ${ }^{a}$

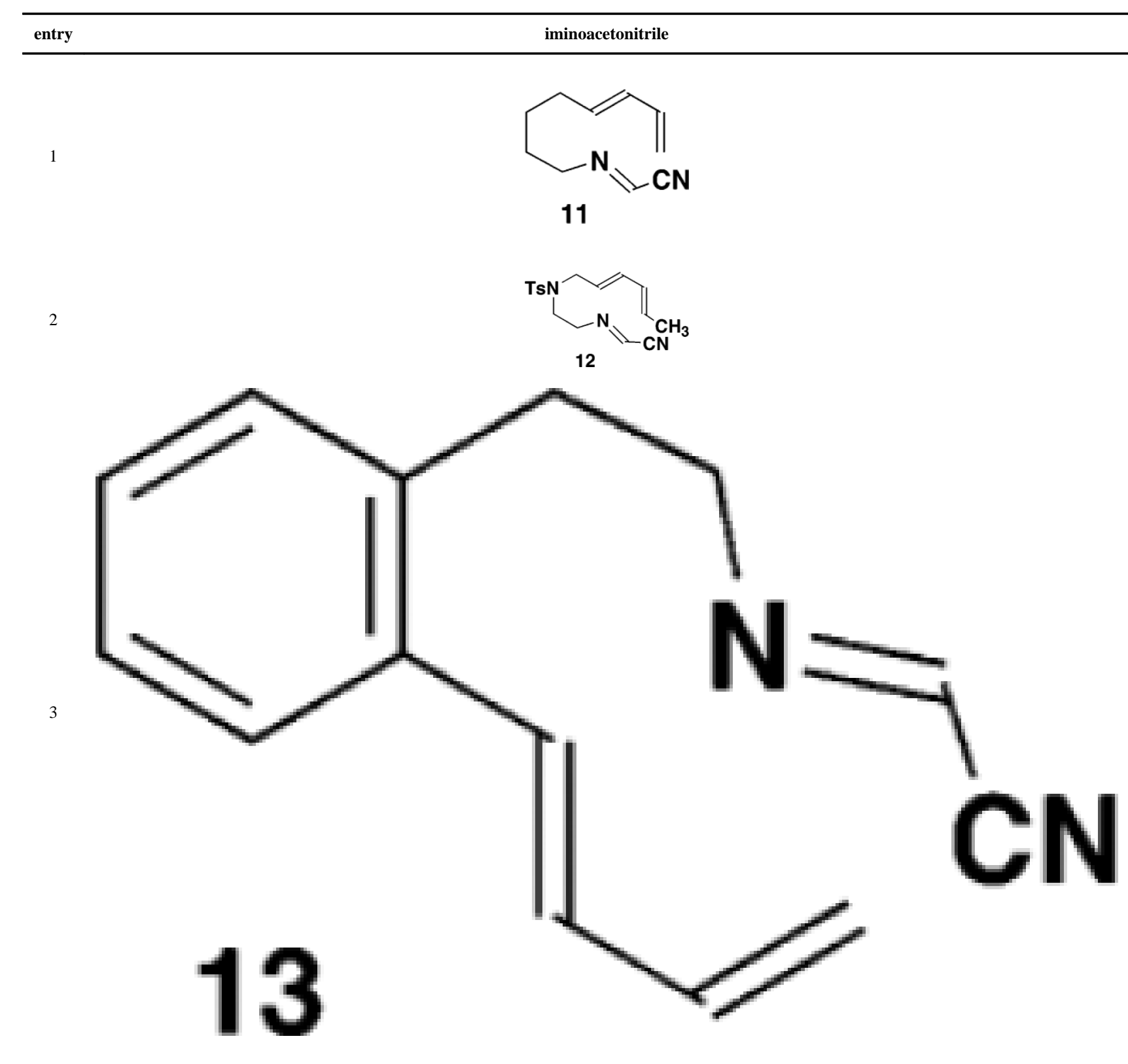




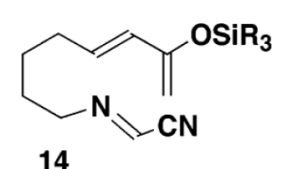

14
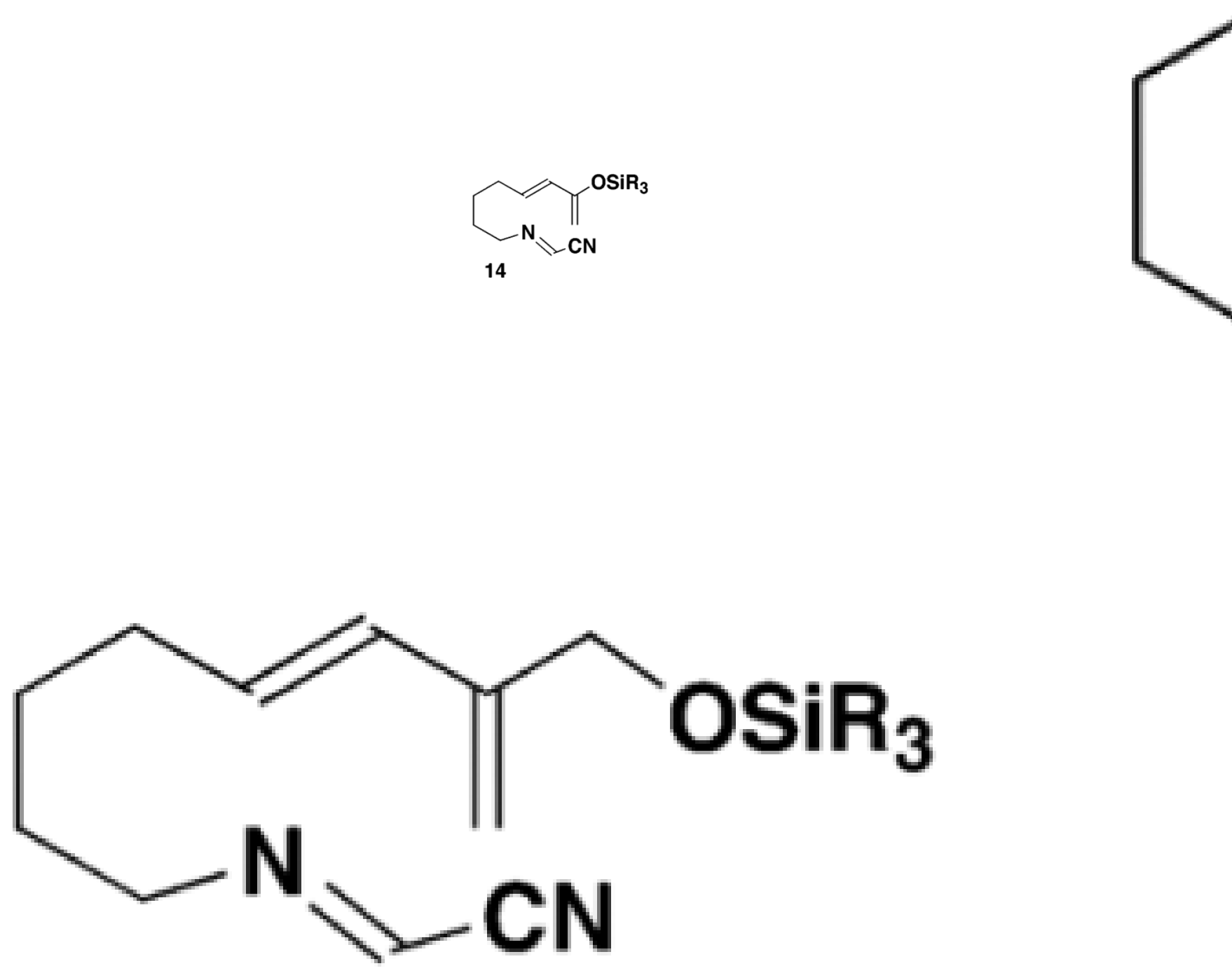

$\mathrm{SiR}_{3}=\mathrm{Sit}-\mathrm{BuMe}_{2}$ 
${ }^{a}$ Cycloadditions were run in toluene $(0.05 \mathrm{M})$ with 3 equiv of BHT in a resealable threaded Pyrex tube at $120{ }^{\circ} \mathrm{C}$ for $15-36 \mathrm{~h}\left(\mathrm{CH}_{3} \mathrm{CN}\right.$, reflux for entry 2).

$b_{\text {Isolated yield of products purified by column chromatography. }}$

${ }^{c}$ Obtained as a 79:21 mixture of isomers at C-1. 